\title{
From videocassette to video stream: issues involved in re-purposing an existing educational video
}

\author{
Kerry Shephard, Roger Ottewill, Peter Phillips and Richard Collier \\ University of Southampton \\ email:kshephard@soton.ac.uk
}

Conventional video recordings can be converted into video streams but the process can be complex and problematic. The author' experience of re-purposing an existing video, Back Care for Health Professionals, for streaming is used to illustrate what was involved and to highlight the important issues. Financial, legal, technical and pedagogic issues are examined.

\section{Introduction}

This paper draws upon our experience of converting an existing educational videocassette into a video stream and presents a case study of the important issues that arose. The process was undertaken to apply some potential benefits of a new technology to support learners in higher education (HE). It was, however, by no means unproblematic and the issues that arose need to receive serious consideration if the potential of streaming technology is to be harnessed for more effective learning opportunities for students.

'Streaming' is a way of transmitting video (or other media files) across the Internet (or by similar means). It is an alternative to downloaded delivery of these media and viewers do not have lengthy 'download waits'. A more comprehensive definition is provided elsewhere (Brown, 2002). The term used here to describe the processes involved in enabling a video recording, made for delivery via videocassette recorder (VCR), to be transmitted across the Internet is 're-purposing'. One process within this broad remit is that of making specific changes to the content of the video recording. This is referred to as 're-engineering'.

The authors all have a strong commitment to the use of video in HE and have actively participated in the re-purposing reported here. They feel that since the Joint Information 
Systems Committee (JISC) and other bodies are investing considerable resources in promoting and evaluating the effectiveness of streamed video to support learning (JISC, 1999), and in re-purposing existing learning materials (JISC, 2002) there is a need to highlight the issues involved.

In this paper attention is given to the context within which the re-purposing of one particular video was undertaken, the processes involved and questions for those considering re-purposing. It does not include evaluation data on how well the resulting learning resource supported student learning as evaluation of the video streaming is still ongoing.

\section{Setting the scene for re-purposing video}

\section{Wide range of available video}

In recent decades considerable use has been made of video for educational as well as for entertainment purposes. Most institutions of $\mathrm{HE}$ have extensive collections of videos, some of which have been made specifically for educational/training purposes while others are mainstream TV programmes recorded under licence by audio-visual technicians. Collections are usually catalogued and issued by librarians in the same way as paper-based media, with various methods being adopted to build up collections and keep tutors abreast of what is available (Tompkins, 1998).

\section{Value of video to support learning}

.Tutors have used videos to enhance the quality of student learning in various ways. Research undertaken at a post-1992 UK university in the mid-1990s showed that, although only about a quarter of teaching staff took advantage of videos, those who did so were motivated by various considerations. These included "bringing the outside world into the learning space ... ; visual representation of ideas and concepts . . .; (and) dramal personification of real-life situations' (Barford and Weston, 1997: 44). Others have stressed the power of video to facilitate 'dynamic modelling' or 'simulation' and 'narrative visualization' (Bates, 1985; Davis, 1991). Video can be used to redress some of the oversimplification that occurs when information from 'real life' is abstracted for conversion into text. It may lead to a better description by tutors and better visualization, recognition and identification by students. Video facilitates story telling, conveys emotions and provides 'real life' examples with which learners can identify.

Advice on the most successful ways to use video is readily available (Race, 1995; Maier and Warren, 2000). Most educational experts agree that video is best shown in short segments so as to maximize learners' concentration and that learners should be encouraged to learn actively from the video by 'interacting' with it. This might involve identifying in advance what they should do while viewing the video and anticipating post-viewing activities.

\section{Technological advances}

Traditionally learners have accessed video via VCR and television or projector and screen. More recently, video has become available in a digital form on compact disc and this has increased the range of situations in which learners can engage with video to support their learning (Shephard, 2001). With advances in digital technology it is now possible for video to be transmitted in a 'stream' rather than as a discrete file. In this way it can be delivered via the Internet with users able to request and view it 'on-demand'. This clearly increases 
its flexibility and offers tutors, and learners, further opportunities for integrating the medium with other forms of learning resource (particularly electronic) and for embedding it in the student learning environment. Lack of user-control was a limitation of video in its traditional form. This is likely to be reduced when it is accessed via a computer. Moreover, 'in this mode it inherits expectations of interactivity' (Laurillard, 2002: 105). It should also enable learning to be supported in a more 'distributed' fashion. Although users require access to a computer with 'broadband' Internet connection, they no longer need their own copy of the videocassette (for examples of how video streaming is being used to support learning in $\mathrm{HE}$ see Shephard, 2003).

\section{Anticipating the issues}

In preparing for the re-purposing, a wide range of non-technical or pedagogical issues and problems were anticipated. Early communication from the UK's Managing Agent and Advisory Service for Moving Pictures and Sound suggested that it was necessary to contact all actors or their agents and possibly pay an additional fee (Gilbart, 2001). Consideration was also given to the rights of 'real people' included in the video, to material that is owned by third parties, to the 'moral rights' of the original producers and to the financial concerns of the video's copyright holder.

\section{Re-purposing processes}

The video selected for re-purposing was Back Care for Health Professionals, which the University of Southampton, in conjunction with the National Back Pain Association, had produced in 1998. There are in effect, two videos. The first deals with 24-hour back care and the second shows moving and handling in a hospital environment. Each video is divided into a number of parts. To supplement the videos there is a written guide (adapted from one produced jointly by the National Back Pain Association and Royal College of Nursing in 1998). This explains their purpose, suggests a possible format for running courses with them and includes text suitable for learner-support.

Since its production Back Care for Health Professionals has been used at the University of Southampton to support learning on a variety of undergraduate and postgraduate courses, including degrees in physiotherapy, occupational therapy, nursing and midwifery, and the Post-Registration Foundation Programme in Basic Moving and Handling. Data gathered from undergraduates indicated that it had played a useful role in enhancing their learning and helping them prepare for their practical examination. However, in order to take advantage of it, they had to borrow copies from the library or from tutors. This made access somewhat problematic. To facilitate distributed access and enhance further its contribution to student leaming, the video was felt to be a suitable candidate for repurposing. In addition, with back care being a very important component of the curriculum for nurses and 'professions allied to medicine', having a flexible, readily accessible video-based learning resource was potentially of considerable value. That said, re-purposing is by no means a 'cheap' option and in securing the necessary resources the contribution of LIFESIGN was crucial.

\section{The role of LIFESIGN}

The JISC-funded LIFESIGN project was charged with the task of developing, cataloguing and evaluating the use of streaming media in learning and teaching in the broad life 
sciences (Lifesign, 2002). In early 2001, discussions were held between a LIFESIGN resource-developer, a University of Southampton media producer and academic staff in the University's School of Health Professions and Rehabilitation Sciences on the feasibility of re-purposing the Back Care for Health Professionals video. A project plan was prepared and presented to LIFESIGN. This anticipated the costs likely to be incurred in the repurposing and by the media producer in addressing various legal matters. LIFESIGN accepted the plan on the understanding that it would lead to opportunities to evaluate both the re-purposing and the use of the resulting video stream to support student learning. The re-purposing was therefore comprehensively documented as part of this remit. Moreover, because LIFESIGN is a multi-partner project the resources of several partners, technical as well as financial, were available.

\section{The role of the producer}

Southampton's media producer played a pivotal role in the re-purposing of the video. He acted as the University's representative on rights issues and was deemed to be in the best position to determine the need to negotiate with actors, their agents and other people, including patients 'captured' on the original video. The media producer also determined the need for 'Restricted Access' to the streamed video. LIFESIGN's project-plan included the stipulation that LIFESIGN would only make the video available to groups of users who had already purchased the videocassette. In the longer term it was hoped that LIFESIGN would be able to promote the streamed video more widely.

\section{Discussion with academic staff}

Academic staff from the School of Health Professions and Rehabilitation Sciences discussed the design of the learning resources and arrangements for evaluation with LIFESIGN resource-developers. Ethical clearance from the School's internal Ethics Committee had to be secured to enable LIFESIGN's evaluation requirement to be met. Academic staff were also actively involved in the re-engineering process.

\section{Re-engineering}

The original analogue videotapes were re-engineered within the University of Southampton's e-Media Group, with the participation of those who were involved in the original commissioning and design of the video. Since the original video was four years old, some techniques for handling patients had changed and a few (which had been best practice in 1998) were no longer recommended. This needed to be addressed, because, when tutors show a conventional video during a teaching session, it is easy to introduce the clip (or interrupt it) by telling the class that a specific part of a technique is no longer carried out. With a video stream, however, this is more difficult and ideally everything shown should be correct. The academic staff and the producer decided which of the scenes had dated and should either be cut out or re-filmed.

Another difference between conventional and streamed video relates to how long students will sit in front of moving pictures and learn from them. To fit into a video stream, analogue video is typically compressed by a factor of 100 and some of the information within it is lost. The picture is made much smaller and is usually one fifth of the original size. Fine detail is lost and the number of colours reduced. Although the human eye can 'find the content' even in such a compressed form, it is much less comfortable to watch than conventional video and viewers may not put up with long sequences of poor quality, 
'jerky' pictures. The media producer also considered that five-minute sequences, which had been effective on conventional video, would be too long for students to watch, online, with no interaction. Thus, re-engineering focused on reducing the length of scenes and facilitating the interaction of learners with the video by ensuring that the scenes related to support materials (for example, guidance notes; reflective and practical questions). While this degree of re-engineering is more likely to be required in a rapidly changing discipline like health care, it seems likely that many other videos would need some re-engineering in order to make them suitable for streaming.

LIFESIGN resource-developers also helped academic staff 'embed' the video stream into the learning resources for identified cohorts of students. Initially this involved writing a Web page that incorporated learning activities along with hyperlinks. These hyperlinks were to ASX redirector files (Microsoft, 2002) that linked learning activities to specified clips from the video. In this way, the potential for combining video streams with the interactive possibilities offered by the computer was beginning to be realized.

\section{Digitization and streaming}

The re-engineered videotapes were digitized by LIFESIGN's media producer and moved to LIFESIGN servers for streaming to the Internet. As 'Restricted Availability' was important to the video's rights holder, the video was streamed from servers where access to the stream could, if necessary, be restricted to individual institutions on the basis of identified IP addresses.

\section{Discussion}

As anticipated, re-purposing gave rise to a range of issues. These are discussed here, together with questions that need to be considered in deciding whether or not to stream a conventional video.

\section{Financial issues}

For any re-purposing project the costs are likely to be considerable, with the amounts involved depending on the professional expertise required and the complexity of the video. In the case reported here funding and support was secured from LIFESIGN. Clearly this would not be generally available. For potential 're-purposers' a key question concerns the extent to which benefits outweigh the costs. In assessing costs, account may have to be taken of the loss of income from sales of the existing videocassette. If the video footage effectively becomes available 'free of charge' over the Internet, then the market for the video will be reduced. Either the availability of the video online must be adequately restricted or the rights holders must be compensated for any loss of income. For the Back Care for Health Professionals video this was an important consideration and access had to be restricted to protect the financial interests of the rights holders.

\section{Legal issues}

Several legal issues arose and in each case the decision reached was based on the best advice available. Occasionally there was a strong feeling that the legal position was not entirely clear. Here the 'least risky' approach was adopted. Most professionally produced videos employ actors. Contracts with these actors generally specify the broad use of the video and do not permit its subsequent use for a purpose, for which it was not initially intended, without further discussion with actors or their agents. In the case reported here 
the situation was that of taking a video, produced for a classroom situation, and 'streaming' it. A point at issue was whether or not 'streaming over the Internet', to identified and restricted users, was broadcasting. The advice that was acted upon was that 'streaming' was 'broadcasting'. Since the Copyright Designs and Patents (CDP) Act 1988 has sections which apply to 'broadcasting material by cable', it is arguable that streamed video is covered by these sections. The Act, however, was passed at a time when the concept of 'streaming' had not arisen and it was not designed to cover this. The legal situation has not yet been tested but it is unlikely that any academic institution would be prepared to do so.

Where video includes other, unpaid, individuals (in this case, 'real' patients) it is normal procedure to obtain permission from them for recording. Here various questions arise. Did the permission anticipate the technological advances that would allow the video to be streamed? Is the streamed distribution so much greater that permission needs to be resought? Would it be possible to contact these people who almost certainly do not have agents? It is easier, certainly more straightforward, to cut footage that includes these people. In the case considered here, such footage was cut.

Another area relates to the rights of members of academic staff who have appeared in videos, which are subsequently streamed. The CDP Act (1988) gives rights to the performer and to their institution/employer. Performance rights did not arise in the current case but would in many other situations.

Some professionally produced videos include material that is owned by third parties (for example, archival film or still pictures, background music). The contracts that give permission for producers to use such material normally impose strict limits on its use - by territory, by time (typically five years from the date of the agreement) and by type of usage (many producers of educational programmes with limited budgets opt for the cheapest type of clearance, which is 'non-broadcast, non-theatrical'). While videos made in the last few years may have had third party material cleared for Internet use, there are many that require these materials to be cleared with payment of additional fees. The introductory section of the Back Care for Health Professionals video, which contained archival shots from the 1996 Olympics, was removed to avoid the cost of re-clearing the material with its rights holder.

While one rights holder might hold the copyright to a video, the original producers have the right to be identified as the originators and/or creators of the work and they have certain 'moral' rights over the integrity of the work (McCracken and Gilbart, 1995; JISC, 1998). Where producers claim this moral right, it would be inappropriate to either reengineer or re-purpose the video without their permission and, possibly, involvement (for a description of the situation as it applies to the broad electronic environment, see JISC, 1998). It is an infringement of producers' rights for users of copyrighted material to modify/adapt the work in a way that could be interpreted as 'derogatory'. The range of possible legal problems inherent in this area is great; particularly where the copyright holder is an institution (in this case a university) and generally represented by the original media producer, or his/her department. The view taken on this occasion was that the original media producer did have the right to be involved with many aspects of the repurposing, indeed, that the project benefited from such involvement. There was, however, a 
need to fund this involvement. For most re-purposing projects this situation would need to be incorporated in the cost-benefit analysis.

\section{Technical issues}

The digitization of an extended videotape to enable it to be streamed effectively to users is technically very demanding. The expertise and resources of the LIFESIGN project partners were crucial in this respect. There are also technical issues that relate to streaming that extend far beyond the capability or experience of many individual users. The resources of institutions with demonstrable commitment to ICT to support learning are probably necessary. This should remain a central question in deciding about potential re-purposing projects.

Streaming offers tutors and learners opportunities that are not so readily available to users of videocassettes. These include enhanced flexibility by dividing the stream into segments and the ability of users to move with ease from one part of the video to another and to and from other learning resources. The extent to which these opportunities are realized relates to some degree to early decisions in the re-purposing process.

Two further technical issues that will become more important for future projects are those of metadata and 'Learning Technology Interoperability Standards'. Metadata, in particular, relates to the extent to which access to sections of online video will be possible via, for example, catalogues and search engines (MEG, 2002). Closely connected to this are Learning Technology Interoperability Standards, which are being addressed in the UK by the Centre for Educational Technology Interoperability Standards (CETIS, 2001). JISC pays for CETIS to be involved in the development and adoption of these standards worldwide and, in so doing, represents the interests of $\mathrm{HE}$ and further education. On a practical level it is important to ensure that digital learning resources can interact with the range of learning resources and learning tools that have not yet been discovered or invented!

\section{Pedagogic issues}

A significant element of any cost-benefit analysis must relate to the learning advantages of the streamed video over conventional resources. It should not be automatically assumed that the new resource will be better (Zenios, 2001; Shephard, 2003). Depending on how it is designed and embedded in the learning programme it may turn out to be a good deal worse. As explained, LIFESIGN's involvement in the re-purposing of the Back Care for Health Professionals video stemmed from an interest in evaluating how well it would support learning, what more it had to offer learners and how it could be effectively embedded in learning programmes. Arguably, such considerations should apply to similar projects, regardless of educational setting. A related issue is the extent to which repurposing results in wider and more effective distribution of the learning resource. Although 'technical' considerations, such as bandwidth and the availability and functioning of equipment and software, are often to the fore, the consequences of limited and inflexible distribution are essentially pedagogic. If streaming does not result in easier access to learning resources, its role in supporting learning and teaching has to be questioned. 


\section{Conclusion}

This paper raises a variety of questions that need to be considered when deciding whether or not conventional videos should be re-purposed. It leads to the conclusion that streaming existing videos is not for the faint-hearted; a wide range of issues will be encountered that must either be overcome or circumvented. Deciding which of these two responses best fits each problem is probably the toughest task and in every situation a rigorous cost-benefit analysis will be necessary.

\section{References}

Barford, J. and Weston, C. (1997), 'The use of video as a teaching resource in a new University', British Journal of Educational Technology, 28 (1), 40-50.

Bates, A. (1985), Using Video in Higher Education, Institute of Educational Technology Paper on Broadcasting No. 243.

Brown, S. (2002), 'Streaming media in UK higher and further education', http://www.techlearn.ac.uk/NewDocs/Streaming111002.doc, last accessed 1 April 2003.

CETIS (2001), 'Home page', www. cetis.ac.uk, last accessed 2 April 2003.

Davis, B. (1991), 'Image learning', http://www.mit.edu:8001/peopleldavis/ImageLearn.html, last accessed 1 April 2003.

Gilbart, M. (2001), personal communication.

JISC (1998), 'JISC/TLTP Copyright Guidelines', http://www:ukoln.ac.uk/services/elib/ papers/otherljisc-tltp/jisc.pdf, last accessed 3 April 2003.

JISC (1999), 'Developing the DNER for learning and teaching', JISC Circular 5/99, http://www:jisc.ac.uk/index.cfm?name=programme_learning_teaching, last accessed 3 April 2003.

JISC (2002), 'Exchange for learning programme (X4L)', JISC Circular 2/02, http://www:jisc.ac.uk/index.cfm?name=circular_2_02, last accessed 3 April 2003.

Laurillard, D. (2002), Rethinking University Teaching, 2nd edn, London: Routledge.

LIFESIGN (2002), 'Networked moving images for the life sciences', www.Lifesign.ac.uk, last accessed 3 April 2003.

Maier, P. and Warren, A. (2000), Integr@ting Technology in Learning and Teaching, London: Kogan Page.

McCracken, R. and Gilbart, M. (1995), Buying and Clearing Rights, London: Blueprint.

MEG (2002), 'The UK's Metadata for Education Group: home page, http:/lwww.ukoln. ac. uk/metadataleducation/, last accessed 3 April 2003.

Microsoft (2002), 'Windows media applications development', http://www.microsoft. com/windon:s/windowsmedia/createldevelop. asp, last accessed 3 April 2003.

Race, P. (1995), 'Making the most of video', SEDA paper 90, 73-90. 
Shephard, K. (2001), 'Submission of student assignments on compact discs: exploring the use of audio, images, and video in assessment and student learning', British Journal of Educational Technology, 32 (2), 161-70.

Shephard, K. (2003), 'Questioning, promoting and evaluating the use of streaming video to support student learning', British Journal of Educational Technology, 34 (3), (in press).

Tompkins, K. (1998), A Bibliography of the Use of Video-Cassettes as a Teaching Medium in Higher Education, Bletchley: Institute of Educational Technology, Open University.

Zenios, M. (2002), 'The use of video streaming in higher education: a report on the evaluation of Click and Go Video case studies and the educational benefits for learners', http:I/www.clickandgovideo.ac.uk/evaluation_casestudies.htm, last accessed 3 April 2003. 